\title{
Solar Energy Technology Choice Development
}

\author{
Mohammed Alsumiri ${ }^{1}$ and Hisham El Khashab ${ }^{2}$ \\ ${ }^{1}$ Electrical and Electronics Engineering Technology Department, Yanbu Industrial College, Yanbu, Saudi Arabia \\ ${ }^{2}$ Power Electronics and Energy Conversion Department, Electronics Research Institute, Dokki, Cairo, Egypt
}

\begin{abstract}
During the last decade with the modern scientific development, different solar energy (SE) technologies were introduced under vast cost variations. The huge need of energy for the use of economic development with the rise of fossil fuel price represents an urgent problem worldwide. The geographical location of Arab countries makes them subject to high average solar irradiance. So that, sustainable energy generation especially solar energy generation can be suitable alternative to conventional energy generation. To implement a solar energy application, the suitable technology choice represents a huge challenge due to high risk against budget cost. In this paper, different solar energy technologies are discussed with the suitable application to obtain the optimal energy conversion system efficiency. Both photovoltaic (PV) and Solar thermal technologies were investigated.
\end{abstract}

\section{Introduction}

The continuous increase in demand of electrical energy is one of the major issues worldwide. The threat of decrease in natural resources from fossil fuel makes this a more severe problem which is facing humanity. To overcome this issue, the industries, researchers and consumers have to reorganize the way how they can generate and consume energy from non-conventional sources. Employment of RE sources and improved energy savings techniques are major key elements in which this challenge can be overcome permanently. In the Arabian Gulf region, where a lot of solar radiation is available, renewable sources such as solar energy should play an important role. Renewable sources have other advantages like reduced global warming and reduced environmental pollution since there is no Carbon Dioxide emission to the environment.

Fossil fuel resources such as petrol and coal are expected to be exhausted by the end of the $21^{\text {st }}$ century from the entire world according to the UNDP (United Nations Developing Program) expectations. It is clear that, renewable power generation, i.e. wind, solar and biomass have an important role in meeting the continuously increasing power demand of the world, especially during this era of technological advancements.

In this paper, the most important solar energy techniques development is discussed. Huge energy is exhausted during winter by water heating; therefore, it might become necessary to introduce solar water heaters through governmental laws to encourage the usage of such technique. Different solar systems such as Photovoltaic (PV) and solar thermal applications are considered as highly beneficial applications of RE. Concerning PV, most development regarding this area is focused on PV system optimization. Also, development took place on the technology of cell fabrications to enhance overall efficiencies of the cells. These enhancements can reduce the cost to a reasonable value among different types, for example, mono-crystalline, poly-crystalline amorphous silicon, copper indium, cadmium telluride, gallium arsenide cells and others. To ensure continuous supply from RE systems, storage techniques must be used in remote area applications such as fuel cell techniques, Nickel Cadmium gel batteries, and others. The issue of storage cost can be reduced by connecting to the grid. But this is possible only for the systems near to the electricity grid.

The annual solar radiation which has an average of 4 - $7.5 \mathrm{KW} / \mathrm{m}^{2}$ is available in Middle East and North Africa (MENA) countries such as Egypt and Saudi Arabia. Moreover, the above average solar radiation is approximately five times higher than the average solar radiation in Europe which is around $1 \mathrm{KW} / \mathrm{m}^{2}$ and in Greece is around $1.7 \mathrm{KW} / \mathrm{m}^{2}$. Hence, solar energy can be nominated as the promising source of renewable energy in this region [1].

The goal of this investigation is to study the proper solar energy technology and to match it with the applications. SE technologies discussed [1-10] may be classified into:

I. Solar thermal energy conversion is to convert solar radiation to:

1- Heat water. This application type has two main technologies:

(a) Flat plate collector.

(b) Evacuated tubes collector.

2- Electricity via converting water to steam.

II. Photovoltaic applications, which means the direct conversion of solar irradiance to electricity.

The cost of each technology represents the main obstacle facing the spread of such technology. The 
efficiency of different technologies varies between 6 $44.4 \%$ for amorphous silicon-based solar cells with multiple-junction production cells with enormous cost variation. Some of these technologies are already commercialized in the market and others are in R\&D phase. This makes SE technology choice a real problem related to the application [2].

\section{Solar thermal energy}

Solar energy cost has fluctuated during the last decades. In 1970s oil crises began which caused a resurgence of interest in other forms of energy such as solar. After recovery, solar energy technology had got less investment. However, scientists with insignificant R\&D budgets sustained the improvement in solar technologies [2].

In 1990s and especially in Japan and Germany, the solar energy has been restored due to many factors, i.e. global warming and environmental awareness, availability of energy resources and industrial countries policy. The energy supply has been forecasted to the year 2100 as presented in fig. 1 .

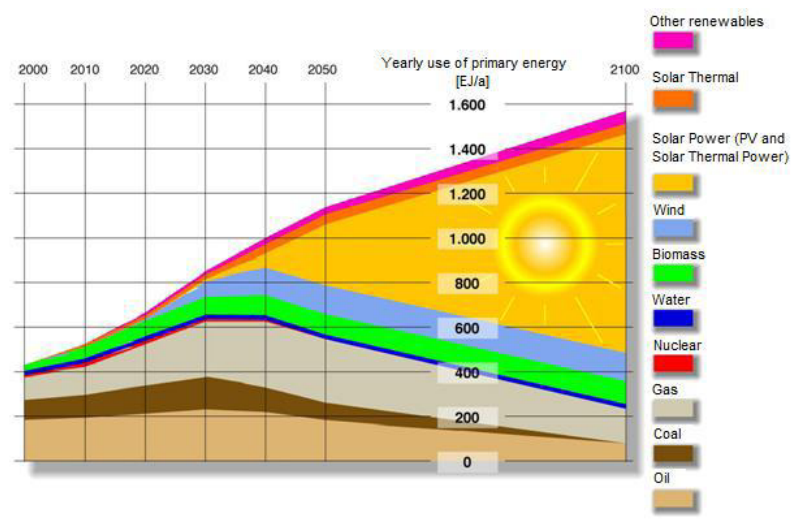

Fig. 1. Energy Supply from 2000 to 2100 .

(Source: International Energy Agency / IEA).

Until 2030, the global energy demand is expected to grow at a rate of $2.5 \%$. Also, it has been estimated that this growth in electricity demand requires cumulative investments of USD 22 trillion which means that approximately USD 1.1 trillion of investment is required per annum. The projected capacity of power generation is $4,800 \mathrm{GW}$ by the end of 2030 . Since one-third of the global greenhouse gas (GHG) emissions is produced by power sector, it becomes necessary to direct these investments to renewable energy technologies

\subsection{Water heating technologies}

Water heating represents huge energy consumption, especially in the winter season. Moreover, some applications such as swimming pools water heating consume high energy which needs further technology improvement. The well-known main water heating technologies are:

1- The Flat-Plate Collectors (FPC) technology, and
2- The Evacuated tubes collector (ETC) technology.

Both technologies are discussed and compared from the point of view of efficiency and cost.

\subsubsection{Flat-Plate Collectors (FPC) technology}

The major component of a typical flat-plate collector system is a glazed dark-colored or particularly coated solar heat-absorber. A network of copper tubes is connected with the plate. The network of tubes is placed in a glazed glass-covered insulator box. The glazed glass is used to protect the collection panels from dust, moisture, and other contaminants. Also, by using glazed glass a greenhouse effect is provided which can minimize energy dissipation. When light radiation falls on it, water or glycol solution that is in the copper tubes is heated up by absorption of thermal energy in the glass and tube. Then solar radiation can be converted into usable heat energy. For the domestic applications, normally one or two collection panels of a size of about $1.2 \times 2.4$ meters ( $4 \times 8$ feet), similar in size to a sheet of plywood, are used.

Unglazed flat-plate collectors don't have the glazed glass covering and insulation. These types are mainly used for low temperature outdoor applications like preheating water, winter pool heating, etc. which consumes a considerable amount of energy. Similar to the glazed type, the conversion from solar to heat energy occurs when the absorber plate is heated up by sunlight. Liquid carrying pipes are attached to the absorber plate that is to allow the heat exchange between the plates and pipes. The collector plates are universally made with black plastic or painted with "selective coatings," which absorb ultra-violet light and preserve heat better than normal black paint. The average efficiency of the mentioned technology is up to $20 \%$ with the price of (100 US\$) of 2 $\mathrm{m}^{2}$ area.

\subsubsection{Evacuated tubes collector (ETC) technology}

This technology is considered as the modification of the flat-plate technology. This type can be used in domestic applications. The main working part is the Evacuated tubes. The thermal energy of sun light is absorbed then converted to heat that can be used in water heating applications. Solar thermal collectors use quite a few types of evacuated tubes, i.e. "twin-glass tube", which is used by Apercus collectors. This type of tube is popular because of many advantages like reliability, performance, and cost-effectiveness.

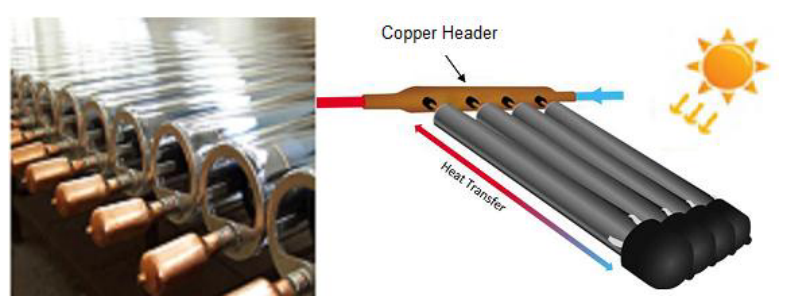

Fig. 2. Evacuated Tubes. 
Figure 2 shows the operation of evacuated tubes that contain dual glass tubes manufactured from extremely strong borosilicate glass. The outer tube is transparent and inner tube is coated with an aluminum nitride (Al$\mathrm{N} / \mathrm{Al}$ ) coating. The sunlight is allowed to pass through the outer layer with negligible reflection and the light is collected by the inner tube. Hence, the reflection losses are minimized by improving the absorption of solar radiation which is achieved by using such arrangement of selective surfaces.

Pumping out the air which is normally present between the glass layers and heating up the top surface of the tube take place during the process of manufacturing. This process allows the two tubes to fuse together in order to create a single evacuated tube without gases. The vacuum is formed by this evacuation process, which helps in improving the performance of the evacuated tubes. The vacuum prevents the leakage of heat energy between the tubes' layers, which means that there will be no exhausted energy. Solar radiation is absorbed and converted to heat by the evacuated tube. Moreover, the vacuum influences the thermal insulation. As a result, the outer tube remains at a temperature just above the ambient temperature while the inner area of the tube reaches $150^{\circ} \mathrm{C}$.

Based on the above, the performance of the evacuated tube water heaters is satisfactory even in cold weather, while the performance of the flat plate collectors is inadequate in these circumstances because of heat losses. The system efficiency may reach up to $65 \%$ with the price of (150 US\$) for 15 tubes of around $2 \mathrm{~m}^{2}$ area [3].

\subsection{Solar thermal electricity generation}

There are two main technologies for solar thermal electricity generation, i.e. Photovoltaic (PV) technology in which sunlight is used to generate electricity, and solar thermal technology in which the solar heat is used for electricity generation or for supporting steam and hot water to supply a turbine to produce electrical power. The overall efficiency of a solar thermal system can be narrowed by a sum of $20 \%$ as a result of boundaries of turbine efficiency. Figure 3, demonstrates the solar thermal conversion diagram to produce electricity.

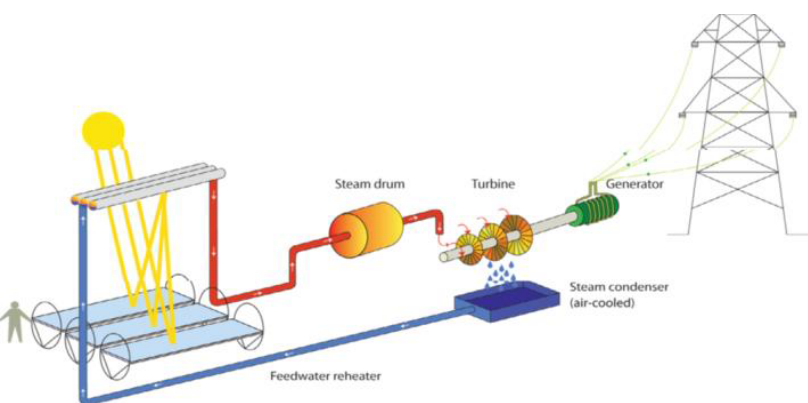

Fig. 3. Solar thermal energy conversion diagram to generate electricity [12].

\section{Photovoltaic technologies}

PV panel crystal technologies are of many types as follows:

1. Mono-crystalline solar cells - Made from a large crystal of silicon (efficiency around 18\%).

2. Poly-crystalline Solar cells - these types of solar cell can be considered as the most widely used solar cell to make solar panels. Their efficiency is slightly less than the other types (typical efficiency between 13\% - $15 \%$ ). In the other hand, it cost slightly cheaper than other technology.

3. Amorphous solar panels (Thin film) - This type is made of a thin film of molten silicon. The sheet is spread directly across large plates to make the panel. The main drawback of this type is the poor overall efficiency as compared to the other two types (efficiency between 6\% - 10\%).

4. CIGS thin-film -This type of thin-film technology is promising due to its highest potential in efficiency enhancement. This type has higher efficiency (efficiency up to 22\%) and very impressive opportunity of future application especially in building-integrated photovoltaic (BIPV) application.

5. High Concentrated PV (HCPV) cells - Up to $29 \%$, HCPV considered being the most efficient technology. In places subjected to high sun irradiation, $\mathrm{HCPV}$ can ensure minimum cost of energy.

6. Third generation PV - This type make use of latest nanotechnology and organic materials. The name is used to represent solar array technologies that are far and wide considered as one of the most talented technology and that is because it has a potential for cost reduction in future.

Figure 4 demonstrates the different PV and solar thermal technologies both in the market and in R\&D phase. Fig. 5 reports the conversion efficiencies of different PV cell technologies with all their developments since 1976 up to 2015 as indicated by NERL (National Renewable Energy Laboratory).

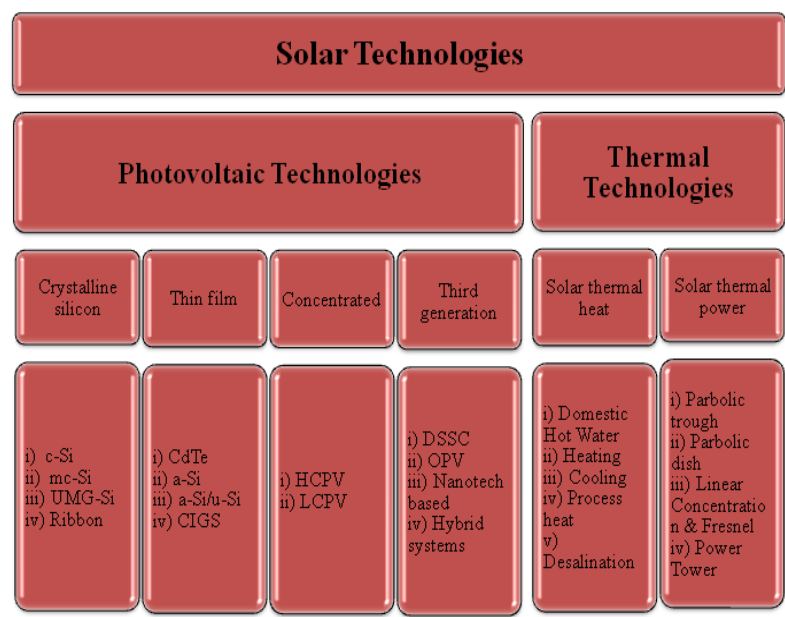

Fig. 4. Selected solar technologies for R\&D activities [13]. 


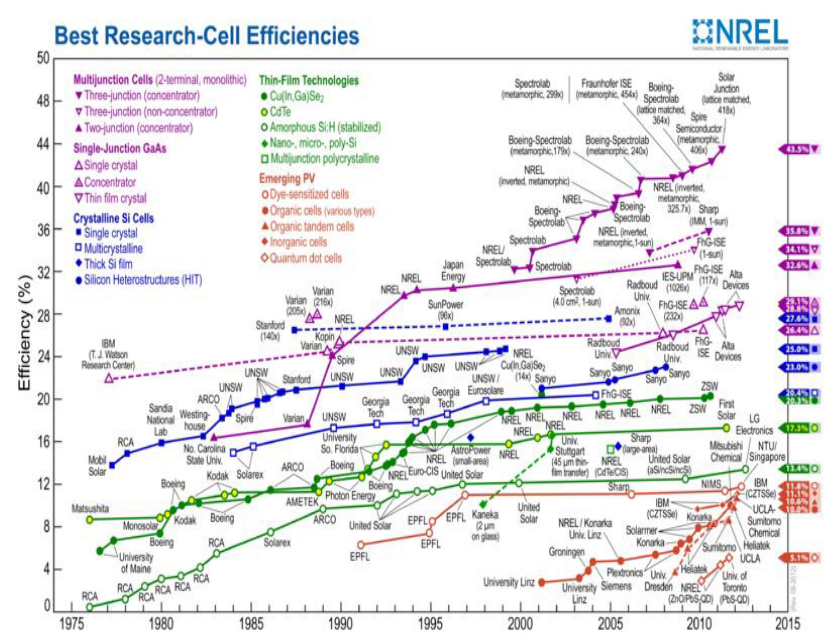

Fig. 5. Solar energy conversion efficiencies from 1976 (Source: National Renewable Energy Laboratory).

\section{Technology cost}

Figure 6 shows the typical efficiency of PV system and the investment costs over time in the US for three different types of PV cells: It is clear that the overall efficiency for almost all types of PV cells have been improved and still it is subject to further improvement in 2020. The major developments will be in the concentrator efficiency and its efficiency is expected to reach $25 \%$ by 2020 .

From figure 6 , it is clear that thin film technology has the cheaper cost, while the concentrator techniques have the higher efficiency and the suitable price. This technique can be considered as one of the promising technology for its attractive cost of energy especially in places that are exposed to a relatively high solar irradiance like the Middle East and North Africa region. The highest efficiency cells may not be economical always, for example a multi-junction cell with $30 \%$ efficiency based on exotic materials such as gallium arsenide or indium selenide produced at low volume might cost one hundred times more than an $8 \%$ efficient amorphous silicon cell in mass production, and able to deliver only about four times the output [11].

Another important factor is heating of the solar cell. As the cell gets heated up the efficiency will decrease. Actually, a $1{ }^{\circ} \mathrm{C}$ temperature increase in solar cell will result in $0.45 \%$ of efficiency decrease. One of the methods used to solve this issue is to use a visibly transparent silica crystal layer over the solar panel. The silica layer emits heat into space in form of infrared radiation allowing the cell to be cooled by approximately $13{ }^{\circ} \mathrm{C}$, since this layer behave like a thermal black body [10].

Third generation technologies is underway to be commercialized. A part from the fact that their efficiency is low, they benefit from low cost and light weight. Concentrating PV technology has the potential to have the highest efficiency among PV module. Other organic or hybrid organic/conventional technologies such as Dye-Sensitized Solar Cells (DSSC) offer low efficiency as well, however their advantages are low cost, light weight and free-form shaping. Therefore, they could fill some market place such as mobile applications, where these features are required [2].

\section{PV System Capital Cost}

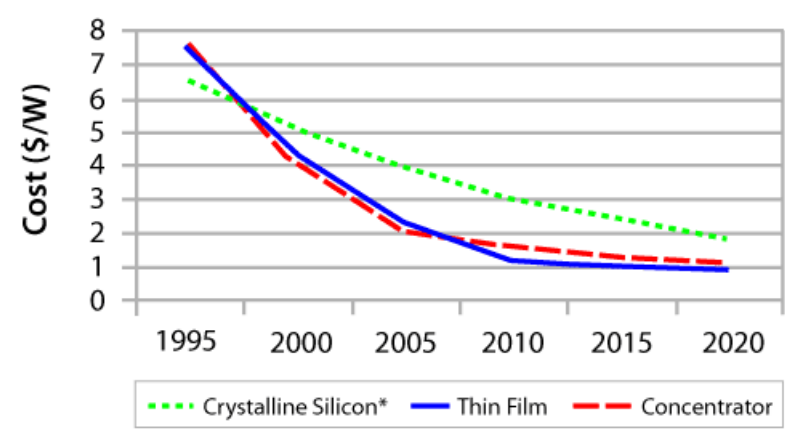

PV System Efficiency

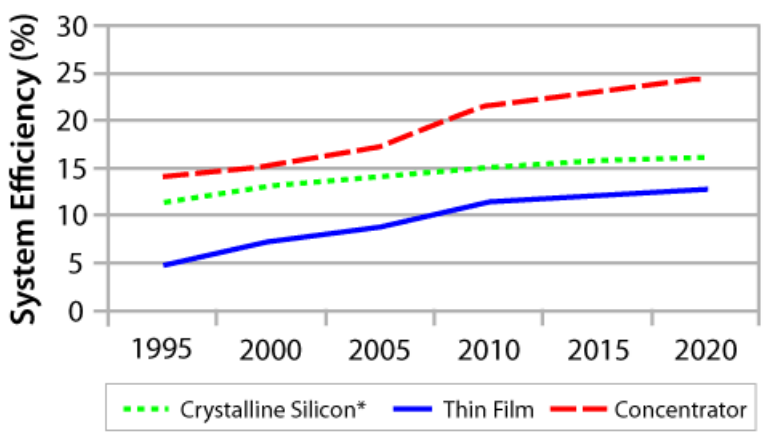

Fig. 6. PV System capital cost and efficiency up to 2020 [3].

\section{Conclusion}

The reasonable application with the suitable prices for heating water is the evacuated tubes panel technique. This technique may be loaned by governmental laws which can make guidance to replace solar water heating instead of electric water heaters. It is expected that the use of solar thermal technologies in both water heating and electricity generation will strongly increase in the MENA region due to the facility of technology use and due to its low cost.

PV technologies have rapid development but with high- cost variations. The Third generation technologies have high operating efficiency at a reasonable cost, which is suitable for low power applications. Other laboratory PV cells such as multi-junction cells with high efficiency and high price levels may be suitable for military and space applications.

\section{References}

1. Eldin, A.H., Refaey, M. and Farghly, A.,"A Review on Photovoltaic Solar Energy Technology and its Efficiency",

https://www.researchgate.net/publication/28779239, Dec. 2015.

2. Irena working paper, "Renewable Energy technologies: cost analysis series", IRENA, vol. 1, 2012 , issue $4 / 5$. 
3. US Office of Indian Energy Policy program, "Efficiency Of Solar PV, Then, Now And Future", Washington DC, 2015.

4. Dena German Energy Agency, "Information about German renewable energy, industries, companies and product(Federal Ministry of Economics and Technology)", pp. 41, 2013-2014, ISIN: B002MNZE4U.

5. Mehta, S.,"PV Technology, Production, and Cost", Outlook: 2010-2015, Greentech Media Research, October 2010, Boston, MA.

6. Arno Smets, Klaus Jäger, Olindo Isabella, René van Swaaij, Miro Zeman, "Solar Energy, Fundamentals, Technology, and systems (UIT Cambridge)", 2014, pp. 109, ISBN: 9781906860325.

7. NREL," Best research-cell efficiency", internet: http://www.nrel.gov/.

8. Green, M.A. et al, " Solar Cell Efficiency Tables progress in Photovoltaics: Research and Applications", Vol. 19, 2011, pp. 84-92.
9. J. Wennerberg, J. Kessler, J. Hedstr“ om, L. Stolt, B. Karlsson, and M. R" Annelid, "Thin film PV modules for low concentrating systems", Solar Energy, vol. 69, supplement 6, 2001, pp. 243-255.

10. T. T. Chow, "A Review of photovoltaic/thermal hybrid solar technology,"Applied Energy, vol. 87, no. 2, 2010, pp. 365-379.

11. Parida, B., Iniyan, S. and Goic, R., 2011. "A review of solar photovoltaic technologies". Renewable and sustainable energy reviews, 15(3), pp.1625-1636.

12. El Khashab, Hisham, and Mohammed Al Ghamedi. "Comparison between hybrid renewable energy systems in Saudi Arabia." Journal of Electrical Systems and Information Technology 2, no. 1 (2015): 111-119.

13. Al-Jarallah, Ahmed \& Al Mohiameed, Elham. (2016). Integrating Solar Photovoltaic with Urban Planning process: A review to derive Conceptual framework for Saudi Cities. 